\title{
The Association Between Leucine and Diabetic Nephropathy (DN) in Different Gender: A Cross- Sectional Study in Chinese Patients with Type 2 Diabetes
}

\section{Xiaoqian Gao}

Tianjin Medical University

\section{Ruiqin Hou}

Peking University People's Hospital

\section{Xin Li}

Tianjin Medical University

Hui-Huan Luo

Tianjin Medical University

Zhong-Ze Fang ( $\square$ fangzhongze@tmu.edu.cn )

Tianjin Medical University https://orcid.org/0000-0003-1113-9262

\section{Research}

Keywords: leucine, diabetic nephropathy (DN), metabolism, type 2 diabetes (T2D)

Posted Date: September 17th, 2020

DOI: https://doi.org/10.21203/rs.3.rs-77499/v1

License: (c) (i) This work is licensed under a Creative Commons Attribution 4.0 International License. Read Full License

Version of Record: A version of this preprint was published at Frontiers in Endocrinology on February 9th, 2021. See the published version at https://doi.org/10.3389/fendo.2020.619422. 


\title{
The association between leucine and diabetic
} nephropathy (DN) in different gender: A

\section{cross-sectional study in Chinese patients with type 2} diabetes

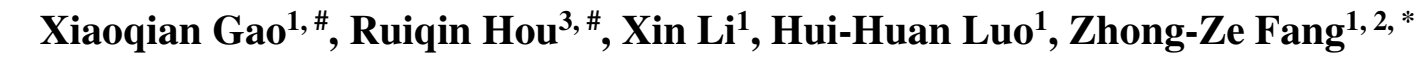

${ }^{1}$ Department of Toxicology and Sanitary Chemistry, School of Public Health, Tianjin Medical University, Tianjin, China;

${ }^{2}$ Tianjin Key Laboratory of Environment, Nutrition and Public Health, Tianjin, China;

${ }^{3}$ Department of Blood Transfusion, Peking University People's Hospital, Beijing, China.

\# These two authors equally contributed to this work.

* Correspondence to:

Zhong-Ze Fang, Department of Toxicology and Sanitary Chemistry, School of Public Health, Tianjin Medical University, Tianjin, 300070, China;

E-mail: fangzhongze@tmu.edu.cn.

\begin{abstract}
Background: This study aimed to evaluate how leucine are associated with diabetic nephropathy (DN) in type 2 diabetes(T2D) patients and the gender difference of this association.
\end{abstract}

Methods: We retrieved 1,032 consecutive patients with T2D from the same tertiary care center and extracted clinical information from electronic medical record. Plasma 
leucine was measured by liquid chromatography-mass spectrometer. Restricted cubic spline (RCS) was conducted to examine potential non-linear relationship between leucine with DN and stratified leucine into categories. Logistic regression was used to obtain odds ratio (OR) and confidence interval (CI). Additive interaction was used to estimate the interaction effect between leucine and gender for DN.

Results: The results showed a negative linear correlation between leucine and DN. After stratifying all patients by gender, this relationship only remained significant in women (OR:0.57, CI:0.41-0.79), and the relationship was still significant in additive interaction analysis.

Conclusion: In conclusion, diabetes patients with high levels of leucine have a lower risk of developing diabetic nephropathy only in female.

Keywords: leucine, diabetic nephropathy (DN), metabolism, type 2 diabetes (T2D)

\section{Background}

Diabetic nephropathy (DN) which is one of common complications of diabetes, greatly increases mortality and medical expenses in type 2 diabetes (T2D) patients(1,2). DN increased enormous societal burden, as it amplifies the risk of other diabetes complications including cardiovascular disease, heart failure, infections(3-7). Since DN is a kind of progressive disease, it is important to search for new approaches that can effectively forecast and prevent the onset of DN. However, noninvasive available markers for accurate prediction and diagnoses of DN in diabetic 
patients are lacking now(8). It is worth noting that many studies have found the burden of diabetes is different in different genders(9). For example, women have higher mortality rate for diabetes-related deaths, including $\mathrm{DN}(10)$. One may speculate that there is maybe something different in disease pathways and predictors of DN between men and women.

With the development of technologies which allow the high-throughput profiling of metabolic status from a blood specimen (metabolomics), more and more researches focused on exploring whether metabolite profiles affect the onset and development of DN via combining epidemiology and metabolomics (11-14)

Insufficient insulin secretion which is a risk factor of DN has been found to be associated with plasma amino acids(15). Different from other amino acids, leucine, one of branched-chain amino acids (BCAAs), is catabolized in skeletal muscle which is important organ for the regulation of blood glucoses(16,17). Recently, leucine has been reported to attenuate $\mathrm{DN}$ progression with improving insulin sensitivity and decreasing adiposity in HFD-fed animal $(18,19)$. However, the specific mechanism on the regulation of leucine towards DN still unclear. At present, there are some population studies expounding the relationship between leucine and diabetes, but there is still a lack of population evidence about the effect of leucine on the risk of $\mathrm{DN}(20)$.

In this study, we established a cross-sectional study in a Chinese population, and aimed to 1) evaluate association between plasm leucine and risk of $\mathrm{DN}$; 2) examine whether this association is affected by gender. 
Methods

69

\section{Study population and settings}

The First Affiliated Hospital of Liaoning Medical University (FAHLMU) is a comprehensive tertiary care center serving 3.1 million people, in Jinzhou, Liaoning Province, China. 1898 T2D patients were diagnosed, among which, 866 patients were excluded due to the ages under 18 years old or lacked height, weight and blood pressure. Based on these exclusion criteria, a total of 1031 research subjects were included. The diagnosis of diabetes was based on the standard published by WHO in 1999 or treated with antidiabetic drugs(21). The Ethics Committee for Clinical Research of FAHLMU approved the ethics of the study, and informed consent was waivered due to the retrospective nature of the study, which is consistent with the Declaration of Helsinki.

\section{Data collection and definitions}

The data retrieved from the electronic medical records for both groups contained demographic and anthropometric information, as well as current clinical factors, medications and complications of diabetes. Demographic included gender, current status of smoking and alcohol consumption. Anthropometric measurements yielded information included height, weight, systolic blood pressure (SBP) and diastolic blood pressure (DBP). Duration of diabetes and diabetic nephropathy were recorded. Clinical parameters contained glycosylated hemoglobin((HbA1c), triglyceride (TG), 
high-density lipoprotein cholesterol (HDL-C), low-density lipoprotein cholesterol (LDL-C), urinary creatinine (UA), serum creatinine (SCR). Details of medication use were documented, including oral anti-diabetic drugs, insulin, and lipid lowering drugs, statins.

In hospitals, anthropometric indices were measured by using standardized procedures. Participants were allowed to wear light clothes and no shoes. Height and weight were measured to the nearest $0.5 \mathrm{~cm}$ and $0.1 \mathrm{~kg}$ respectively. Blood pressure was measured behind the right arm of an adult cuff using a standard mercury sphygmomanometer and post-measurement at an appropriate size, after a 10 minutes rest in a sitting position. Age was calculated from the date of birth to the date of hospitalization or medical examination, and was calculated in years. The body mass index (BMI) was calculated as the ratio of weight $(\mathrm{kg})$ to squared height(meters) classifying overweight and obesity according to the criteria recommended by the National Health Commission in China(22). The diagnostic criteria for diabetic nephropathy was based on the national guidelines for the prevention and management of diabetes at the basic level(23).

\section{Laboratory assay}

Dried blood spots were used in the assay of metabolomics, which were prepared from capillary whole blood through 8 -h fasting. We measured the metabolites by direct infusion mass spectrometry technology equipped with the AB Sciex 4000 QTrap system (AB Sciex, Framingham, MA, USA). High-purity water and acetonitrile were 
purchased from Thermo Fisher (Waltham, MA, USA), and utilized as diluting agent and mobile phase. 1-Butanol and acetyl chloride were obtained from Sigma-Aldrich (St Louis, MO, USA). Isotope-labeled internal standard samples of amino acids (NSK-A) were purchased from Cambridge Isotope Labo-ratories (Tewksbury, MA, USA), while standard samples of the leucine were purchased from Chrom Systems

(Grafelfing, Germany). In brief, $8.5 \mathrm{~mL}$ of venous blood was drawn from each participant at 08:00 to 09.30 hours in the morning after 8-h fasting. Laboratory tests were carried out at a special diagnostic laboratory. The level of lipid profiles was analyzed by an automatic biochemistry analyzer (Hitachi 7150, Tokyo, Japan). We also assayed the level of HDL-C and LDL-C by the selective solubilization method (Determiner L-HDL, LDL test kit; Kyowa Medex, Tokyo, Japan).

\section{Statistical Analysis}

Data with the normal distribution was represented by the mean \pm standard deviation (SD), or use the median (interquartile range). Categorical variable was in numbers and their $95 \%$ confidence intervals (CI). Traditional risk factors for type 2 diabetes 
unadjusted OR values and the OR after adjusted age, gender, BMI $(<18.5,18.5-24.0$, 24.0-28.0, >28.0 kg/m²), duration of diabetes, smoking, drinking, SBP, DBP, TG, LDL-C, HDL-C, HbA1c, UA, SCR, insulin, statins. Restricted cubic splines curve (RCS) is a smoothing curve that can provide more intuitive relationship curve. We chose 4 knots in RCS as suggested by Harrell. We have used it to obtain cutoffs for metabolites related to the risk of developing diabetes (24). We selected a cut-off point by visual checking of the curve where the odds of DN changed.

We repeated logistic regression analysis in males and females respectively to obtain OR values. Additive interaction analysis was used to verify the relationship between gender (male or female) and leucine (in 2 groups by RCS cutoff) for DN. We calculated the relative excess risk due to interaction (RERI), attributable proportion due to interaction (AP) and synergy index (S) to estimate additive interactions(25). RERI $>0, A P>0$ or $\mathrm{S}>1$ indicates a significant additive interaction(25). To avoid the bias caused by non-incident DN. We exclude the patients who with duration of DN >2 years to check the changes of the effect sizes of leucine for risk of DN.

A $\mathrm{P}<0.05$ was considered as statistically significant. All analyses were performed using R version 3.6 and SAS version 9.4 (Institute Inc., Cary, North Carolina, USA).

\section{Results}

\section{Characteristics of the study population}

The mean age and BMI of 1031 participants were 57.2 years (SD:13.8) and 25.3 
$\mathrm{kg} / \mathrm{m}^{2}$ (SD:3.9). Of them, $46.8 \%$ were female. There was a total of 188 patients with DN and 92 of them are women. Table 1 summarized the selected characteristics of DN and controls by sex. In women, cases tended to be older, had higher BMI and longer duration of diabetes, higher SBP, HbA1c, HDL-C, LDL-C, and SCR, and were less likely to use insulin and statins than patients without DN. In men, patients with DN had longer duration of T2D, higher SCR, UA and were less likely to use insulin than controls.

\section{The relationship between diabetic nephropathy and leucine}

The slope of RCS curve has a process from small to large and then small, which reaches its maximum at about $175 \mu \mathrm{mol} / \mathrm{L}$. Among all patients, leucine level of $84.8 \%$ patient were below $175 \mu \mathrm{mol} / \mathrm{L}$. (Figure 1)

In univariable regression, leucine was inversely associated with the risk of DN (OR: $0.8,95 \%$ CI:0.67, 0.95). After further adjustment for traditional risk factors, the negative association was strengthened in multivariable analysis (OR:0.76, 95\%CI: 0.62, 0.92). (Table 2)

\section{Interaction between leucine and gender}

Leucine was negative associated with the risk of $\mathrm{DN}$ in diabetes patients in the female population (OR: $0.51,95 \% \mathrm{CI}: 0.41,0.79)$ while the relationship was not significant in male(table3). In female the risk of DN was decrease rapidly until around $175 \mu \mathrm{mol} / \mathrm{L}$ of leucine and then started to relatively flat afterwards. In male, the association 
177 between BMI and mortality disappeared (Figure 2). Using 175 as a cutoff value of 178 leucine, leucine $(<175$ or $\geq 175 \mu \mathrm{mol} / \mathrm{L}$ ) and gender(male or female) had a significant 179 additive interaction for DN (AP: 0.90, 95\%CI: 0.18-1.62; RERI: 0.60 , 95\%CI: 0.08-1.12; and S: $0.36,95 \%$ CI: $0.11-1.20)$.

\section{Sensitivity analysis}

After excluding 10 patients who had DN for more than 2 years, the effect size was larger. In the multivariable analysis, the OR value became $0.74(0.61,0.91)$, and the OR value in the female population changed to 0.56 (CI: $0.40,0.77$ ).

\section{Discussion}

In this study, we found that high plasma level of leucine was associated with decreased odds of DN in female T2D. Female with lower plasma leucine had three-fold more risk of DN than those who had higher. However, the association between leucine and risk of DN was not significant in male. We also found that additive interaction between sex and leucine for DN risk was significant to prove this association.

Although there are no population trials to compare results. The inverse association was consistent with many animal studies. Previous study has shown that leucine supplementation could alleviate early DN damage (19). There are some related experiments that can indirectly explore the effect of leucine on diabetic nephropathy. A study found that the supplement of leucine in diet can active the 
$\operatorname{AMPK}(26)$, which was considered as a newly identified regulator of renal hypertrophy in diabetes $(26,27)$. Higher plasma leucine has been found to reverse the disorder of tricarboxylic acid (TCA) cycle metabolism and carnitine metabolic disorders in mice with $\mathrm{DN}(28,29)$. Hyperlipidemia is also a common cause of $\mathrm{DN}$, and the supplementation of leucine in animal tests can reduce blood lipid(27). By increasing energy consumption, leucine could reduce the likelihood of obesity and increase insulin sensitivity, which can reduce the risk of $\mathrm{DN}(1,30,31)$.

Some mechanistic studies suggested that leucine is a potent activator of mTORC1 which control the protein synthesis(32). Leucine directly binds Sestrin2, and then Sestrin2 releases GATOR2 which is a positive regulator of mTORC1 and insulin secretion(16,33-37). After activation, mTORC1 promotes protein synthesis and controls autophagy by phosphorylating a series of targets. Leucine also activates mTORC1 via other mechanisms, such as initiation of the colocalization of the lysosome with mTORC1(38). This is a possible speculation why leucine influence insulin secretion and then further affect the risk of DN. In other studies, it was found that the supplement of lacto-leucine during lactation take the change of insulin levels in the offspring which were affected by gender(28). This difference may be caused by

217 higher expression in female $(39,40)$. The possibility of this difference was further confirmed in our population study. The negative correlation between leucine and DN was found only in women. The mechanism by which leucine protects DN need further clarify until now. 

potential novel markers, leucine, will be helpful in diagnosis and disease prediction; 2) As an essential amino acid, leucine has only dietary sources(28). Noticeable, protein are often restricted in diabetic patients which possibly cause a deficiency of leucine for patient(1). This result may give clinical suggestion that When taking a protein-restricted diet, consider separate amino acid supplements; 3) Male mice were

227 often used in animal experiments, which also causes the potential relationships 228 between leucine and DN may be erased by gender selection. And it reminds us to consider exploring in more mechanism research and animal experiments to determine whether disease pathways can differ and if therapeutic targeting strategies are equally 231 effective in both sexes.

The present study has some limitations. Firstly, the cross-sectional study can only prove the statistical association between plasma leucine and $\mathrm{DN}$, but not the exact 234 causal relationship. Due to the lack of research in population, this study provides 235 clues and direction to the further relevant study. Secondly, due to the lack of time and energy, some of the influencing factors were not investigated, such as diet, which may have an impact on results. Nevertheless, we can indirectly adjust the bias of those

238 factor through BMI. Thirdly, our subjects were hospitalized with T2D, who may have 239 more severe diabetes and nephropathy complications. We try to exclude patients with 240 diabetic nephropathy for more than 2 years in the sensitivity analysis. Results showed 241 that the OR value reduced, and the results were still very significant in the total study 242 population and female population. Therefore, the report of this study may have a low 
estimate of the protective effect of leucine on diabetic nephropathy.

\section{Conclusion}

This study shows that leucine was inversely association with the risk of DN in women with T2D. Considering the shortcoming of cross-sectional studies, more studies with stronger causal justification and in other populations are needed for further confirmation.

\section{Perspectives and significance}

Gender differences in the effect of leucine on occurrence and development of diabetic nephropathy have been researched for some animal experiments and mechanism research. Our population research validates the results of before studies and provide some scientific and clinical significance. In previous animal experiments, male animals were often used, which may affect the discovery of this relationships. accuracy of clinical diabetic nephropathy prediction and diagnosis. And due to the nature of essential amino acids, the intervention of leucine can be taken by simple oral means. If the results replicate in population randomized controlled trial, we have reason to believe that improvement of plasma level of leucine in female patients could be used as a method to protect and control DN. 
Ethics approval and consent to participate

265 The Ethics Committee for Clinical Research of LMUFAH approved the ethics of the $266 \quad 373$ study

\section{Consent for publication}

269 Informed consent was waivered by the above ethics committee due to the 270 retrospective nature of the study.

\section{Availability of data and materials}

Data are available on request to the corresponding author.

\section{Competing interests}

276 All other authors have no conflicts of interest to declare.

\section{Funding}

279 This work was supported by the National Science Foundation of China (grant number. and analysis, decision to publish, or preparation of the manuscript.

\section{Authors' contributions}

285 Zhong-Ze Fang conceived the project, designed experiments. Xiaoqian Gao wrote the 
manuscript and analyzed data. Hui-Huan Luo collect the information and contributed to the writing of this manuscript. Xin Li contributed to the data interpretation. Ruiqin Hou gave critical comments on the first draft. All authors edited the final version of the manuscript. All authors read and approved the final manuscript.

\section{Acknowledgement}

The authors thank all doctors, nurses and research staff at the Liaoning Medical University (FAHLMU) in Jinzhou, for their participation in this study.

\section{REFERENCE}

1. Gross JL, De Azevedo MJ, Silveiro SP, Canani LH, Caramori ML, Zelmanovitz T. Diabetic nephropathy: Diagnosis, prevention, and treatment. Diabetes Care. 2005;28(1):164-76.

2. Magee C, Grieve DJ, Watson CJ, Brazil DP. Diabetic Nephropathy: a Tangled Web to Unweave. Cardiovasc drugs Ther. 2017 Dec;31(5-6):579-92.

3. Thomas MC, Cooper ME, Zimmet P. Changing epidemiology of type 2 diabetes mellitus and associated chronic kidney disease. Nat Rev Nephrol [Internet]. 2016;12(2):73-81. Available from: http://dx.doi.org/10.1038/nrneph.2015.173

4. Umanath K, Lewis JB. Update on Diabetic Nephropathy: Core Curriculum 2018. Am J Kidney Dis [Internet]. 2018;71(6):884-95. Available from: https://doi.org/10.1053/j.ajkd.2017.10.026 
5. Braunwald E. Diabetes, heart failure, and renal dysfunction: The vicious circles. Prog Cardiovasc Dis [Internet]. 2019;62(4):298-302. Available from: https://doi.org/10.1016/j.pcad.2019.07.003

6. Winocour PH. Diabetes and chronic kidney disease: an increasingly common multi-morbid disease in need of a paradigm shift in care. Diabet Med. 2018;35(3):300-5.

7. Barrios C, Pascual J, Otero S, Soler MJ, Rodríguez E, Collado S, et al. Diabetic nephropathy is an independent factor associated to severe subclinical atheromatous disease. Atherosclerosis. 2015 Sep;242(1):37-44.

8. Zubiri I, Posada-Ayala M, Benito-Martin A, Maroto AS, Martin-Lorenzo M, Cannata-Ortiz $\mathrm{P}$, et al. Kidney tissue proteomics reveals regucalcin downregulation in response to diabetic nephropathy with reflection in urinary exosomes. Transl Res. 2015 Nov;166(5):474-484.e4.

9. Maric-Bilkan C. Sex Differences in Diabetic Kidney Disease. Mayo Clin Proc. 2020;95(3):587-99.

10. Tian L, Nikolic-Paterson DJ, Tesch GH. Establishing equivalent diabetes in male and female Nos3-deficient mice results in a comparable onset of diabetic kidney injury. Physiol Rep. 2019;7(18):1-8.

11. Allen J, Davey HM, Broadhurst D, Heald JK, Rowland JJ, Oliver SG, et al. High-throughput classification of yeast mutants for functional genomics using metabolic footprinting. Nat Biotechnol. 2003;21(6):692-6.

12. Zhang X, Zhang Y, Wang P, Zhang S-Y, Dong Y, Zeng G, et al. Adipocyte 
Hypoxia-Inducible Factor $2 \alpha$ Suppresses Atherosclerosis by Promoting Adipose Ceramide Catabolism. Cell Metab. 2019 Nov;30(5):937-951.e5.

13. Sun L, Xie C, Wang G, Wu Y, Wu Q, Wang X, et al. Gut microbiota and intestinal FXR mediate the clinical benefits of metformin. Nat Med. 2018 Dec;24(12):1919-29.

14. Qi X, Yun C, Sun L, Xia J, Wu Q, Wang Y, et al. Gut microbiota-bile acid-interleukin-22 axis orchestrates polycystic ovary syndrome. Nat Med. 2019 Aug;25(8):1225-33.

15. Newgard CB. Interplay between lipids and branched-chain amino acids in development of insulin resistance. Cell Metab. 2013;15(5):606-14.

16. Yang J, Chi Y, Burkhardt BR, Guan Y, Wolf BA. Leucine metabolism in regulation of insulin secretion from pancreatic beta cells. Nutr Rev. 2010;68(5):270-9.

17. Pedroso JAB, Zampieri TT, Donato J. Reviewing the effects of l-leucine supplementation in the regulation of food intake, energy balance, and glucose homeostasis. Nutrients. 2015;7(5):3914-37.

18. Chen K-H, Chen Y-L, Tang H-Y, Hung C-C, Yen T-H, Cheng M-L, et al. Dietary Leucine Supplement Ameliorates Hepatic Steatosis and Diabetic Nephropathy in db/db Mice. Int J Mol Sci. 2018 Jun;19(7).

19. Mi N, Zhang XJ, Ding Y, Li GH, Wang WD, Xian HX, et al. Branched-chain amino acids attenuate early kidney injury in diabetic rats. Biochem Biophys Res Commun. 2015 Oct;466(2):240-6. 
20. Macotela Y, Emanuelli B, Bång AM, Espinoza DO, Boucher J, Beebe K, et al. Dietary leucine - an environmental modifier of insulin resistance acting on multiple levels of metabolism. PLoS One. 2011;6(6).

21. Alberti KG, Zimmet PZ. Definition, diagnosis and classification of diabetes mellitus and its complications. Part 1: diagnosis and classification of diabetes mellitus provisional report of a WHO consultation. Diabet Med. 1998 Jul;15(7):539-53.

22. "National Health Commission of the People's Republic of China." Criteria of weight for adults [Internet]. National Health Commission of the People's Republic of China. 2013. p. 4. Available from: http://www.nhfpc.gov.cn/ewebeditor/uploadfile/2013/08/20130808135715967. pdf

23. Tong SJ, Key S. 国家基层糖尿病防治管理指南（2018）. 2018;57(12):885-93.

24. Li J, Cao YF, Sun XY, Han L, Li SN, Gu WQ, et al. Plasma tyrosine and its interaction with low high-density lipoprotein cholesterol and the risk of type 2 diabetes mellitus in Chinese. J Diabetes Investig. 2019;10(2):491-8.

25. Andersson T, Alfredsson L, Källberg H, Zdravkovic S, Ahlbom A. Calculating measures of biological interaction. Eur J Epidemiol. 2005;20(7):575-9.

26. Lee MJ, Feliers D, Mariappan MM, Sataranatarajan K, Mahimainathan L, Musi $\mathrm{N}$, et al. A role for AMP-activated protein kinase in diabetes-induced renal hypertrophy. Am J Physiol - Ren Physiol. 2007;292(2):617-27. 
27. Macotela Y, Emanuelli B, Bång AM, Espinoza DO, Boucher J, Beebe K, et al. Dietary leucine - an environmental modifier of insulin resistance acting on multiple levels of metabolism. PLoS One. 2011;6(6).

28. López N, Sánchez J, Palou A, Serra F. Gender-associated impact of early leucine supplementation on adult predisposition to obesity in rats. Nutrients. 2018;10(1).

29. Zhang Y, Guo K, LeBlanc RE, Loh D, Schwartz GJ, Yu YH. Increasing dietary leucine intake reduces diet-induced obesity and improves glucose and cholesterol metabolism in mice via multimechanisms. Diabetes. 2007;56(6):1647-54.

30. Cummings NE, Williams EM, Kasza I, Konon EN, Schaid MD, Schmidt BA, et al. Restoration of metabolic health by decreased consumption of branched-chain amino acids. J Physiol. 2018;596(4):623-45.

31. Pedersen HK, Gudmundsdottir V, Nielsen HB, Hyotylainen T, Nielsen T, Jensen BAH, et al. Human gut microbes impact host serum metabolome and insulin sensitivity. Nature [Internet]. 2016;535(7612):376-81. Available from: http://dx.doi.org/10.1038/nature18646

32. Donato J, Pedrosa RG, Cruzat VF, Pires IS de O, Tirapegui J. Effects of leucine supplementation on the body composition and protein status of rats submitted to food restriction. Nutrition. 2006;22(5):520-7.

33. Michael Neinast*, Danielle Murashige* and ZA. Branched Chain Amino Acids. Physiol Behav. 2016;176(1):139-48. 
34. Amaral AG, Rafacho A, MacHado De Oliveira CA, Batista TM, Ribeiro RA, Latorraca MQ, et al. Leucine supplementation augments insulin secretion in pancreatic islets of malnourished mice. Pancreas. 2010;39(6):847-55.

35. Xu G, Kwon G, Cruz WS, Marshall CA, McDaniel ML. Metabolic regulation by leucine of translation initiation through the mTOR-signaling pathway by pancreatic $\beta$-cells. Diabetes. 2001;50(2):353-60.

36. Yang J, Dolinger M, Ritaccio G, Mazurkiewicz J, Conti D, Zhu X, et al. Leucine Stimulates Insulin Secretion via Down-regulation of Surface Expression of Adrenergic $\smile 2 \mathrm{~A}$ Receptor through the mTOR (Mammalian Target of Rapamycin) Pathway. J Biol Chem. 2012;287(29):24795-806.

37. Filiputti E, Rafacho A, Araújo EP, Silveira LR, Trevisan A, Batista TM, et al. Augmentation of insulin secretion by leucine supplementation in malnourished rats: possible involvement of the phosphatidylinositol 3-phosphate kinase/mammalian target protein of rapamycin pathway. Metabolism [Internet]. 2010;59(5):635-44. Available from:

http://dx.doi.org/10.1016/j.metabol.2009.09.007

38. Efeyan A, Zoncu R, Sabatini DM. Amino acids and mTORC1: from lysosomes to disease. Trends Mol Med [Internet]. 2013;18(9):524-33. Available from: https://www-ncbi-nlm-nih-gov.myaccess.library.utoronto.ca/pmc/articles/PMC 3432651/pdf/nihms390711.pdf

39. Lee MJ, Feliers D, Mariappan MM, Sataranatarajan K, Mahimainathan L, Musi $\mathrm{N}$, et al. A role for AMP-activated protein kinase in diabetes-induced renal 
40. Phillips SM, Atkinson SA, Tarnopolsky MA, MacDougall JD. Gender differences in leucine kinetics and nitrogen balance in endurance athletes. J Appl Physiol. 1993;75(5):2134-41.

FIGURE1|Odds ratio curves of leucine for diabetic nephropathy in Chinese type 2

diabetic patients.

The black curve was derived from univariable analysis. The blue one was derived

431 from multivariate analysis that adjusted for age, gender, body mass index, duration of 432 diabetes, smoking, drinking, systolic blood pressure, diastolic blood pressure, low-density lipoprotein cholesterol, high-density lipoprotein cholesterol and triglyceride, glycosylated hemoglobin, urinary creatinine, serum creatinine, insulin, 435 statins(i.e., the odds ratio for diabetic nephropathy was 1).

FIGURE2|Odds ratio curves of leucine for diabetic nephropathy in Chinese type 2 diabetic patients in different gender.

439 The black curve was derived from univariable analysis, the blue one derived from 
440 multivariate analysis that adjusted for age, gender, body mass index, duration of 441 diabetes, smoking, drinking, systolic blood pressure, diastolic blood pressure, 442 low-density lipoprotein cholesterol, high-density lipoprotein cholesterol, triglyceride, 443 glycosylated hemoglobin, urinary creatinine, serum creatinine, insulin, statins(i.e., the 444 odds ratio for diabetic nephropathy was 1). 
Table1 Clinical and biochemical characteristics of participants according to the occurrence of diabetic nephropathy.

\begin{tabular}{|c|c|c|c|c|c|c|}
\hline \multirow{3}{*}{ Variables } & \multicolumn{2}{|l|}{ Women } & \multirow{3}{*}{$p^{a}$} & \multicolumn{2}{|l|}{ Men } & \multirow{3}{*}{$p^{a}$} \\
\hline & Non-DN (391) & $\underline{\mathrm{DN}}(92)$ & & \multirow{2}{*}{$\begin{array}{l}\text { Non-DN (452) } \\
\text { Mean/number (SD or \%) }\end{array}$} & \multirow{2}{*}{$\frac{\mathrm{DN}(96)}{\text { Mean/number }(\mathrm{SD} \text { or } \%)}$} & \\
\hline & Mean/number (SD or \%) & Mean/number (SD or \%) & & & & \\
\hline Age (years) & $59.16 \pm 12.81$ & $60.54 \pm 9.8$ & $<0.01$ & $54.75 \pm 14.81$ & $57.72 \pm 14.33$ & 0.074 \\
\hline Weight (kg) & $63.64 \pm 10.56$ & $67.11 \pm 13.21$ & 0.007 & $75.72 \pm 12.79$ & $75.43 \pm 11.04$ & 0.84 \\
\hline Height (cm) & $160.00(156.00,163.00)$ & $160.00(158.00,165.00)$ & 0.235 & $172.00(170.00,175.00)$ & $172.00(170.00,175.00)$ & 0.616 \\
\hline BMI $\left(\mathrm{kg} / \mathrm{m}^{2}\right)$ & $24.83 \pm 3.83$ & $25.87 \pm 4.36$ & 0.024 & $25.53 \pm 3.83$ & $25.54 \pm 3.41$ & 0.977 \\
\hline $\mathrm{BMI}<18.5$ & $70(17.9 \%)$ & $24(26.1 \%)$ & & 104(23.01\%) & $23(23.96 \%)$ & \\
\hline $\mathrm{BMI} \geq 18.5$ and $<24.0$ & $150(38.3 \%)$ & $32(34.8 \%)$ & & $211(46.68 \%)$ & $37(38.54 \%)$ & \\
\hline $\mathrm{BMI} \geq 24.0$ and $<28.0$ & $162(41.3 \%)$ & $34(37.0 \%)$ & & $122(26.99 \%)$ & $35(36.46 \%)$ & \\
\hline $\mathrm{BMI} \geq 28.0$ & $9(2.3 \%)$ & $2(2.2 \%)$ & & $15(3.32 \%)$ & $1(1.04 \%)$ & \\
\hline Smokingyes & $25(6.4 \%)$ & $8(8.7 \%)$ & 0.577 & $243(53.8 \%)$ & $55(57.3 \%)$ & 0.604 \\
\hline Drinkingyes & $13(3.3 \%)$ & $2(2.2 \%)$ & 0.811 & $221(48.9 \%)$ & $54(56.2 \%)$ & 0.231 \\
\hline Duration of diabetes (years) & $6.97 \pm 7.44$ & $8.93 \pm 7.71$ & 0.024 & $3.00(0.00,10.00)$ & $10.00(2.75,14.25)$ & $<0.001$ \\
\hline $\mathrm{SBP}(\mathrm{mmHg})$ & $140.00(122.00,155.00)$ & $149.50(129.50,174.00)$ & 0.001 & $138.71 \pm 22.46$ & $142.1 \pm 22.42$ & 0.179 \\
\hline DBP (mmHg) & $80.79 \pm 13.52$ & $83.23 \pm 12.59$ & 0.116 & $83.79 \pm 13.3$ & $82.25 \pm 14.82$ & 0.312 \\
\hline $\mathrm{HbA} 1 \mathrm{c}(\%)$ & $7.53 \pm 3.22$ & $8.64 \pm 2.68$ & 0.002 & $7.66 \pm 3.07$ & $8.24 \pm 3.11$ & 0.096 \\
\hline Triglyceride (mmol/L) & $1.22(0.82,2.08)$ & $1.52(1.02,2.31)$ & 0.089 & $1.22(0.82,2.00)$ & $1.31(0.89,1.97)$ & 0.561 \\
\hline HDL-C (mmol/L) & $0.9 \pm 0.45$ & $1.07 \pm 0.52$ & 0.001 & $0.84(0.45,1.06)$ & $0.85(0.50,1.07)$ & 0.265 \\
\hline LDL-C (mmol/L) & $2.42 \pm 1.24$ & $2.79 \pm 1.31$ & 0.013 & $2.25(1.13,2.95)$ & $2.42(1.27,3.04)$ & 0.505 \\
\hline $\mathrm{SCR}(\mu \mathrm{mol} / \mathrm{L})$ & $53.51(43.41,70.95)$ & $57.55(45.59,119.00)$ & 0.028 & $68.72(58.00,91.10)$ & $87.78(64.41,314.17)$ & $<0.001$ \\
\hline $\mathrm{UA}(\mu \mathrm{mol} / \mathrm{L})$ & $307.00(238.00,445.50)$ & $340.60(264.25,532.35)$ & 0.073 & $345.00(274.75,499.00)$ & $391.50(326.00,778.00)$ & 0.004 \\
\hline
\end{tabular}




\begin{tabular}{|c|c|c|c|c|c|c|}
\hline Leucine $(\mu \mathrm{mol} / \mathrm{L})$ & $124.87 \pm 43.17$ & $112.69 \pm 31.61$ & $<0.001$ & $143.18 \pm 49.85$ & $137.24 \pm 46.56$ & $<0.001$ \\
\hline$<175 \mu \mathrm{mol} / \mathrm{L}$ & $349(79.9 \%)$ & $42(93.33 \%)$ & & $352(77.87 \%)$ & $100(22.12 \%)$ & \\
\hline \multicolumn{7}{|l|}{ diabetic medications } \\
\hline Acarbose & $129(33.0 \%)$ & $43(46.7 \%)$ & \multicolumn{2}{|c|}{$0.018150(33.2 \%)$} & $42(43.8 \%)$ & 0.064 \\
\hline Metformin & $131(33.5 \%)$ & $41(44.6 \%)$ & \multicolumn{2}{|c|}{$0.061155(34.3 \%)$} & $31(32.3 \%)$ & 0.797 \\
\hline Insulin & $275(70.3 \%)$ & $85(92.4 \%)$ & $<0.001$ & $321(71.0 \%)$ & $90(93.8 \%)$ & $<0.001$ \\
\hline Statins & $131(33.5 \%)$ & $45(48.9 \%)$ & \multicolumn{2}{|c|}{$0.008152(33.6 \%)$} & $41(42.7 \%)$ & 0.116 \\
\hline
\end{tabular}

Data are mean (standard deviation), median (interquartile range) or n (\%). BMI, body mass index. SBP, systolic blood pressure. DBP, diastolic blood pressure. HbA1c, glycated hemoglobin. HDL-C, high- density lipoprotein cholesterol. LDL-C, low-density lipoprotein cholesterol. UA, uric acid. SCR, serum creatinine.

${ }^{\text {a }}$ Based on thet-test, Wilcoxon rank-sum test or $\chi^{2}$ test as appropriate. 
1 Table2Odds ratio of leucine for the risk of diabetic nephropathy.

\begin{tabular}{cll}
\hline & OR $(95 \% \mathrm{CI})$ & $p$ \\
\hline $\begin{array}{c}\text { Univariable model } \\
\text { Leu, per } \mu \mathrm{mol} / \mathrm{L}\end{array}$ & $\begin{array}{l}0.8(0.67,0.95) \\
\text { reference }\end{array}$ & 0.012 \\
$<175 \mu \mathrm{mol} / \mathrm{L}$ & $0.59(0.36,0.97)$ & 0.036 \\
$\geq 175 \mu \mathrm{mol} / \mathrm{L}$ & & \\
Multivariable model1 & & 0.016 \\
$\quad \begin{array}{l}\text { Leu, per } \mu \mathrm{mol} / \mathrm{L} \\
<175 \mu \mathrm{mol} / \mathrm{L}\end{array}$ & $0.8(0.67,0.96)$ & reference \\
$\geq 175 \mu \mathrm{mol} / \mathrm{L}$ & $0.61(0.37,1.01)$ & 0.045 \\
Multivariable model2 & & \\
$\quad \begin{array}{l}\text { Leu, per } \mu \mathrm{mol} / \mathrm{L} \\
<175 \mu \mathrm{mol} / \mathrm{L}\end{array}$ & $0.76(0.63,0.92)$ & 0.006 \\
$\geq 175 \mu \mathrm{mol} / \mathrm{L}$ & $0.56(0.33,0.94)$ & 0.044 \\
Multivariable model3 & & \\
Leu, per $\mu \mathrm{mol} / \mathrm{L}$ & $0.76(0.62,0.92)$ & 0.006 \\
$<175 \mu \mathrm{mol} / \mathrm{L}$ & reference & \\
$\geq 175 \mu \mathrm{mol} / \mathrm{L}$ & $0.58(0.34,0.99)$ & 0.038 \\
\hline
\end{tabular}

2 Multivariable Model 1 was adjusted for age, gender, body mass index, duration of

3 diabetes, smoking, drinking.

4 Multivariable Model 2 was adjusted for variables in Model 1 and concentrations of

5 systolic blood pressure, diastolic blood pressure, triglyceride, low-density lipoprotein

6 cholesterol, high-density lipoprotein cholesterol, glycosylated hemoglobin.

7 Multivariable Model 3 was adjusted for variables in Model 2 and concentrations of 8 urinary creatinine, serum creatinine, insulin, statins.

10 Table3 Odds ratio of leucine for the risk of diabetic nephropathy.

\begin{tabular}{|c|c|c|c|c|}
\hline & \multicolumn{2}{|l|}{ female $(n=483)$} & \multicolumn{2}{|l|}{ male $(n=548)$} \\
\hline & $\mathrm{OR}(95 \% \mathrm{CI})$ & $p$ & $\mathrm{OR}(95 \% \mathrm{CI})$ & $p$ \\
\hline \multicolumn{5}{|l|}{ Univariable model } \\
\hline $\begin{array}{l}\text { Leu, per } \mu \mathrm{mol} / \mathrm{L} \\
<175 \mu \mathrm{mol} / \mathrm{L}\end{array}$ & $\begin{array}{l}0.71(0.55,0.93) \\
\text { reference }\end{array}$ & 0.008 & $\begin{array}{l}0.88(0.7,1.11) \\
\text { reference }\end{array}$ & 0.274 \\
\hline$\geq 175 \mu \mathrm{mol} / \mathrm{L}$ & $0.28(0.08,0.92)$ & 0.037 & $0.76(0.43,0.34)$ & 0.329 \\
\hline Multivariable model1 & & & & \\
\hline
\end{tabular}




\begin{tabular}{|c|c|c|c|c|}
\hline $\begin{array}{l}\text { Leu, per } \mu \mathrm{mol} / \mathrm{L} \\
<175 \mu \mathrm{mol} / \mathrm{L}\end{array}$ & $\begin{array}{l}0.7(0.53,0.91) \\
\text { reference }\end{array}$ & 0.009 & $\begin{array}{l}0.90(0.71,1.14) \\
\text { reference }\end{array}$ & 0.380 \\
\hline$\geq 175 \mu \mathrm{mol} / \mathrm{L}$ & $0.29(0.09,0.98)$ & 0.045 & $0.78(0.44,1.38)$ & 0.394 \\
\hline \multicolumn{5}{|l|}{ Multivariable model 2} \\
\hline $\begin{array}{l}\text { Leu, per } \mu \mathrm{mol} / \mathrm{L} \\
<175 \mu \mathrm{mol} / \mathrm{L}\end{array}$ & $\begin{array}{l}0.59(0.43,0.81) \\
\text { reference }\end{array}$ & 0.001 & $\begin{array}{l}0.90(0.71,1.12) \\
\text { reference }\end{array}$ & 0.399 \\
\hline$\geq 175 \mu \mathrm{mol} / \mathrm{L}$ & $0.26(0.07,0.87)$ & 0.030 & $0.75(0.42,1.36)$ & 0.345 \\
\hline \multicolumn{5}{|l|}{ Multivariable model3 } \\
\hline $\begin{array}{l}\text { Leu, per } \mu \mathrm{mol} / \mathrm{L} \\
<175 \mu \mathrm{mol} / \mathrm{L}\end{array}$ & $\begin{array}{l}0.57(0.41,0.79) \\
\text { reference }\end{array}$ & $<0.001$ & $\begin{array}{l}0.92(0.71,1.18) \\
\text { reference }\end{array}$ & 0.493 \\
\hline$\geq 175 \mu \mathrm{mol} / \mathrm{L}$ & $0.24(0.07,0.83)$ & 0.024 & $0.81(0.44,1.48)$ & 0.489 \\
\hline
\end{tabular}

11 Multivariable Model 1 was adjusted for age, gender, body mass index, duration of

12 diabetes, smoking, drinking.

13 Multivariable Model 2 was adjusted for variables in Model 1 and concentrations of 14 systolic blood pressure, diastolic blood pressure, triglyceride, low-density lipoprotein

15 cholesterol, high-density lipoprotein cholesterol, glycosylated hemoglobin.

16 Multivariable Model 3 was adjusted for variables in Model 2 and concentrations of 17 urinary creatinine, serum creatinine, insulin, statins. 
Figures

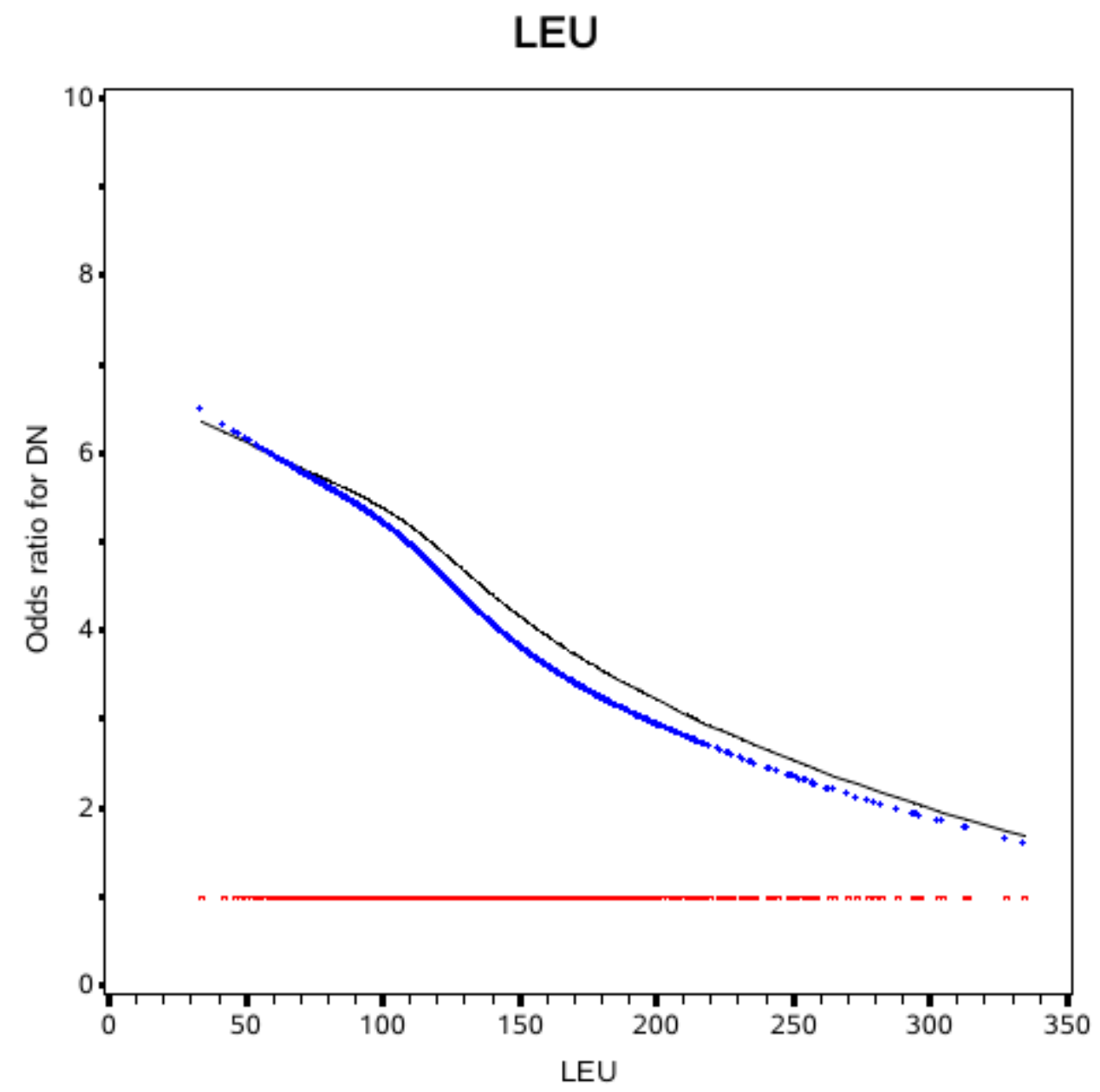

Figure 1

Figure 1 
male

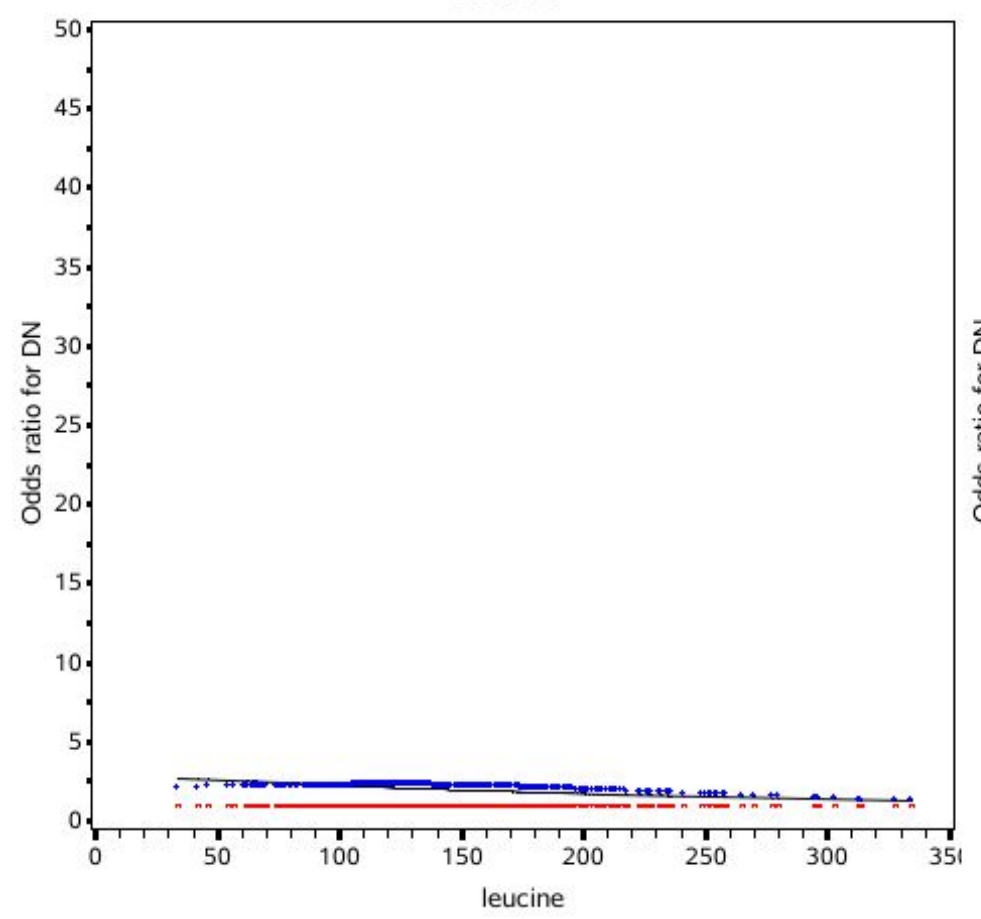

female

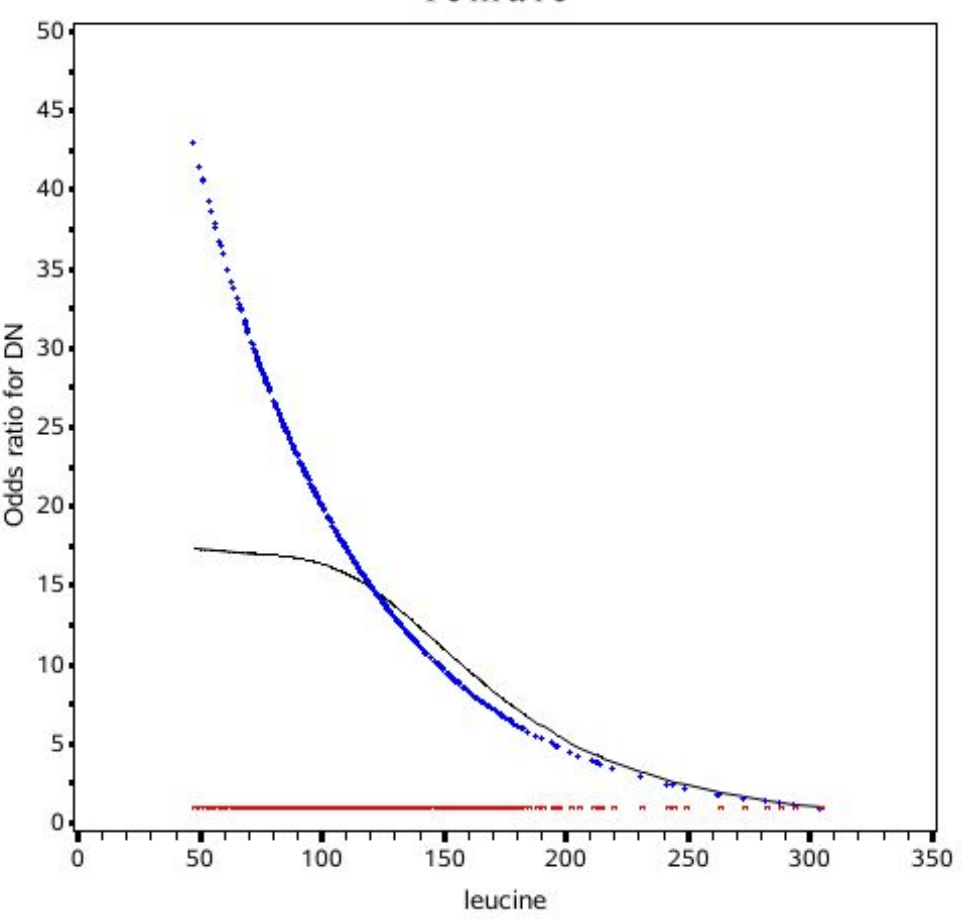

Figure 2

Figure 2 